\title{
Reversal of threatening blindness after initiation of eculizumab in Purtscher-like retinopathy secondary to atypical hemolytic uremic syndrome
}

\author{
J. E. Ramos de Carvalho • R. O. Schlingemann • M. Oranje • \\ F. J. Bemelman - M. J. van Schooneveld
}

Received: 6 September 2016/ Accepted: 13 February 2017/Published online: 8 March 2017

(C) The Author(s) 2017. This article is published with open access at Springerlink.com

\begin{abstract}
Purtscher-like retinopathy, a rare manifestation of systemic thrombotic microangiopathy, is a potentially visually debilitating condition with no effective proven treatment. Distinct pathogenic pathways have been proposed as etiological factors. We revisit the etiology of Purtscher-like retinopathy based on the rapid response and profound visual improvement after initiation of systemic intravenous eculizumab, an inhibitor of the complement cascade, in a patient with Purtscher-like retinopathy secondary to familial atypical hemolytic uremic syndrome (aHUS) due to a mutation in complement factor $\mathrm{H}$. We hypothesize that the efficacy of eculizumab in this patient provides evidence for pathogenic events in the retina similar to those encountered in the renal microvasculature of aHUS patients, namely complement-mediated thromboembolization as a result of activation of the complement cascade in endothelial cells with release of tissue factor and development and amplification of a procoagulant state. To the best of
\end{abstract}

J. E. Ramos de Carvalho $(\varangle) \cdot$ R. O. Schlingemann . M. J. van Schooneveld

Department of Ophthalmology, Academic Medical

Centre, University of Amsterdam, Amsterdam,

The Netherlands

e-mail: j.e.decarvalho@amc.uva.nl

M. Oranje · F. J. Bemelman

Division of Internal and External Medicine, Department of Nephrology, Academic Medical Centre, University of Amsterdam, Amsterdam, The Netherlands our knowledge, this is the first report in the literature of eculizumab as an effective therapeutic strategy in Purtscher-like retinopathy.

Keywords Atypical hemolytic uremic syndrome · Complement - Eculizumab · Purtscher-like retinopathy

\section{Introduction}

Purtscher and Purtscher-like retinopathy are rare, often bilateral, multifactorial downstream occlusive thromboembolic retinopathies, mediated in a large proportion of cases by uncontrolled complement activation. The designation Purtscher retinopathy implies a traumatic etiology, whereas Purtscher-like retinopathy depicts non-traumatic causes [1].

Several mechanisms have been brought forward as hypothetical triggers of Purtscher and Purtscher-like retinopathy [1-3]. Although the pathogenesis is likely multifactorial and differs according to the underlying predisposing condition, embolization of the retinal microcirculation has been proposed as the common pathogenic ground for the retinal findings [4-7]. Potential sources of toxic and/or obstructive emboli include air, fat, fibrin, platelet and leukocyte aggregates [1], emboli arising from orbital steroid injection [8] and retrobulbar anesthesia [8-11], and amniotic fluid emboli after childbirth [12]. Uncontrolled 
complement activation has been proposed to play a major role in the pathogenesis of Purtscher-like retinopathy by mechanisms involving endothelial damage and activation of the clotting cascade $[5,6,13,14]$ and development of leukocyte and platelet aggregates $[1,4]$. Other proposed mechanisms include intravascular volume surge such as in sudden expansion of retinal veins [1], hyperviscosity [15], intracephalic shock waves such as in sudden increase in intracranial pressure with resulting precapillary occlusion at the level of the lamina cribrosa [16], capillary endothelial damage [17] and vascular endothelial dysregulation and ensuing endothelininduced vasculopathy [16]. Associated systemic entities include acute pancreatitis [18-25], pancreatic adenocarcinoma [26], systemic lupus erythematosus [27], renal failure [28, 29], amniotic fluid embolization [12], thrombotic thrombocytopenic purpura [30-33], hemolytic uremic syndrome (HUS) [31, 34] and cryoglobulinemia [35-37]. In specific disorders, the diagnosis of Purtscher-like retinopathy accompanies multisystem organ failure and therefore portends a poor prognosis [38].

Patients present with sudden visual acuity loss of variable severity, hours to days after the onset of the associated etiology. Some patients may be asymptomatic which likely results in underreporting [4]. The majority of cases (83-92\%) show funduscopic evidence of retinal nerve fiber layer infarcts (cotton-wool spots) and intraretinal hemorrhages [1, 2]. Purtscher "flecken" corresponds to areas of intraretinal whitening with a clear zone (within $50 \mu \mathrm{m}$ ) on either side of the retinal arterioles, venules and precapillary arterioles. These lesions result from precapillary arteriolar occlusion and, albeit pathognomonic, can be identified in only $50 \%$ of cases [2]. Other less frequent findings include macular edema, optic disk swelling and a pseudo-cherry red spot. Fluorescein angiography shows evidence of an occlusive thromboembolic retinopathy with areas of retinal non-perfusion and leakage of dye from retinal arterioles, capillaries, venules and optic disk [4].

Up to $40 \%$ cases may be associated with normalization of all retinal findings and restoration of normal visual acuity; however, a significant proportion of patients develop optic atrophy, mottling of the retinal pigment epithelium (RPE), retinal thinning and narrowing of retinal arteries $[4,39]$. The prognosis for the individual patient is difficult to predict due to the lack of clear and validated predictors. Treatment strategies range from watchful waiting, plasmapheresis or high dose systemic corticosteroids [2, 40-42].

Hemolytic uremic syndrome is characterized by non-immune hemolytic anemia, thrombocytopenia and renal impairment. Most cases (90\%) are secondary to infection with Shiga toxin-producing bacteria as well as other bacteria, such as Streptococcus pneumoniae [43]. Non-infectious causes, classified as atypical hemolytic uremic syndrome (aHUS), are linked to uncontrolled complement activation. The familial type of aHUS has a particularly poor prognosis, with progression to end-stage disease occurring in 50 and $80 \%$ of cases [44]. Purtscher-like retinopathy has been reported to occur in a minority of patients with HUS [45-47].

We present a case of Purtscher-like retinopathy secondary to aHUS due to complement factor $\mathrm{H}$ $(\mathrm{CFH})$ mutation and resulting complement overactivation, successfully treated with systemic intravenous administration of eculizumab (Soliris; Alexion Pharmaceuticals, Cheshire, CT, USA), an inhibitor of terminal complement activation. We hypothesize that eculizumab may be an alternative therapeutic strategy for severe Purtscher-like retinopathy associated with deregulated activation of the complement pathway. Based on the response achieved after initiation of treatment, an alternative etiology for Purtscher-like retinopathy is proposed after a short review of the literature.

\section{Case description}

A 20-year-old Caucasian woman presented with complaints of subacute painless loss of vision of her left eye. She was referred to our clinic for intravitreal ganciclovir treatment after a putative diagnosis of bilateral cytomegalovirus retinitis had been made by an ophthalmologist at her local hospital the previous day. She was one of three sisters with familial aHUS due to a missense mutation (c.3572 C > T, Ser1191Leu) in exon 23 of Complement Factor $\mathrm{H}$ ( $\mathrm{CFH}$ gene). At 6 years of age, she underwent bilateral nephrectomy followed 1 year later by a living donor renal transplant. After 1 year, she developed a systemic cytomegalovirus infection with relapse of aHUS. Her immunosuppression was tapered to a calcineurin-free regimen, and chronic maintenance plasmapheresis 
was started. Four years later, a transplant biopsy showed chronic allograft nephropathy with global glomerulosclerosis and tubular atrophy. There were no treatment options other than supportive care and her renal function slowly declined hereafter. At 19 years of age, she reached end-stage renal failure, immunosuppression was further tapered and she was started on dialysis. The maintenance plasmaphereses were halted. During dialysis, she complained of seeing "black spots" and was referred to a local ophthalmologist who in turn referred her to our service. Her family history included two sisters, one of them her identical twin, with aHUS and $C F H$ mutation. Her brother was an asymptomatic carrier for the $C F H$ mutation, and her younger sister was not affected. She had no past history of ocular illnesses.

On ophthalmologic examination, best corrected visual acuity was $20 / 15$ and $20 / 200^{-2}$ in the right and left eyes, respectively. There was no relative afferent pupillary defect. Intraocular pressure was normal. The anterior chambers and vitreous were clear in both eyes. Fundus examination revealed cotton-wool spots and mild flame-shaped hemorrhages in both eyes. The left eye showed mild macular cystoid macular edema. The retinal vessels were of a normal caliber in both eyes. An inconspicuous choroidal nevus was present in the nasal retina of the right eye. Fluorescein angiography revealed early hypofluorescence, areas of non-perfusion, capillary obstruction and dropout, inner retinal ischemia in the parafoveal and perifoveal zone corresponding with the cotton-wool spots and perifoveal capillary leakage in the late frames. The left eye showed mild cystoid macular edema nasal to the fovea (Figs. 1, 2). Mild peripapillary leakage was noted in the late frames of the left eye. Besides a small hemorrhage peripherally, all other angiographic findings were confined to the posterior pole, namely within the macula and immediately nasal to the optic disk. Normal fluorescein transit times were observed. The degree of macular ischemia and perifoveal capillary dropout was more pronounced in the left eye in keeping with the objective visual acuity loss in that eye. These clinical findings, together with her medical history, were consistent with Purtscher-like retinopathy. At the time of referral to our clinic, she was awaiting a second living donor renal transplantation. The ophthalmic findings provided evidence that the hemolytic uremic syndrome was undertreated and indirect evidence that she had uncontrolled systemic

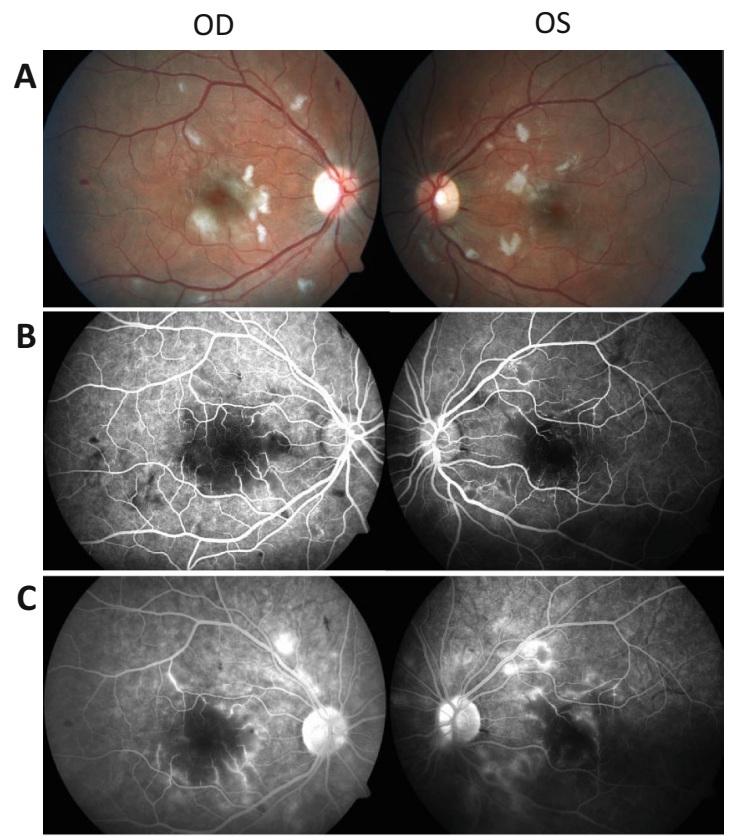

Fig. 1 Retinal photographs and fluorescein angiogram appearance at initial presentation. a Fundus appearance at presentation. Note the diffuse retinal nerve fiber layer infarcts, inner retinal ischemia and scattered retinal hemorrhages. Visual acuity was $20 / 15$ and $20 / 200^{-2}$ in the right and left eye, respectively. b Mid-phase intravenous fluorescein angiogram of the same patient at initial presentation. Note the parafoveal and perifoveal areas of capillary obstruction and retinal ischemia correspondent to the areas of inner retinal ischemia seen in the fundus picture. c Mid- to late-phase fluorescein angiogram in the same patient. Note the parafoveal pericapillary staining and mild macular edema with late leakage in the left eye. Angiographic findings were mostly confined to the macula and immediately nasal to the optic disk

complement activation. In order to prevent further progression of her retinopathy, and due to the severe loss of vision in her left eye, treatment with eculizumab was initiated. Eculizumab, a C5 complement inhibitor, has been praised as highly effective in the treatment of hemolytic uremic syndrome, also after transplantation. After 4 months, while on chronic eculizumab therapy, a transplantectomy was performed followed by a second renal transplantation. Both procedures proceeded uneventfully.

On follow-up, she reported a steady continuous improvement of her visual acuity. Five days after eculizumab administration, best corrected visual acuity was stable in her right eye and pinhole visual acuity improved to $20 / 50^{+2}$ in her left eye. Fundus examination revealed a decrease in the size of the cotton- 


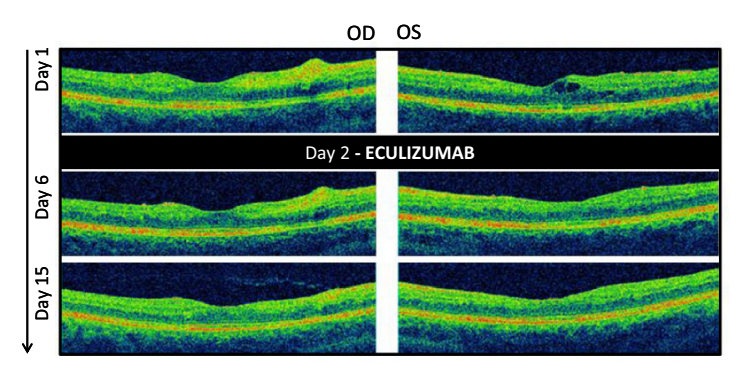

Fig. 2 Optical coherence tomography findings at initial presentation and at day 6 and 15. Inner retinal ischemia was evident in both eyes, corresponding to the cotton-wool spots demonstrated in the color photographs. The right eye, with normal visual acuity at presentation, had no evident macular edema. The left eye, with severe visual acuity loss, had mild cystoid macular edema which regressed rapidly after eculizumab administration. At day 15, visual acuity in the left eye had improved significantly alongside resolution of the macular edema and inner retinal ischemia

wool spots, and optical coherence tomography showed total resolution of the cystoid macular edema in the left eye (Fig. 2). On the 14th day after treatment, she reported total resolution of all her previous visual complaints. Best corrected visual acuity was stable in her right eye and had improved to $20 / 15^{-2}$ in her left eye. Fundus examination revealed an improvement of all clinical findings, including the nerve fiber layer infarcts, flame-shaped hemorrhages and macular edema. She was referred back to her local ophthalmologist. At 18 months, visual acuity remained stable and no visual complaints were reported (Fig. 3).

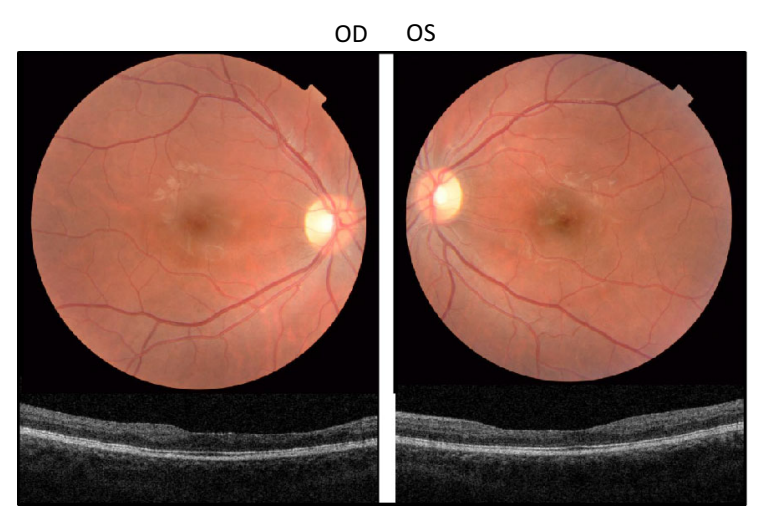

Fig. 3 Retinal photographs and optical coherence tomography 18 months after initial presentation. Color photographs of the right and left maculae show a normal appearance, albeit a significant thinning is evident on optical coherence tomography. The patient is asymptomatic and has normal visual acuity $(20 / 15$ in the right eye and $20 / 20 / 15^{-2}$ in the left eye)

\section{Conclusions}

This single case describes the favorable visual outcome achieved after systemic treatment with eculizumab in a patient with severe Purtscher-like retinopathy secondary to familial aHUS and $\mathrm{CFH}$ mutation. In our view, the retinal findings were secondary to uncontrolled systemic complement activation and as a result complement-mediated leukoembolization and/or complement activation of the coagulation cascade in endothelial cells with ensuing development of a prothrombotic state (Fig. 4).

Leukoembolization as a cause of embolic retinal occlusion has been proposed as a potential pathogenic mechanism in Purtscher-like retinopathy [6, 48, 49]. However, recent experimental studies suggest endothelial activation of the coagulation cascade by complement with formation of microthrombi as the most plausible mechanism in the pathogenesis of aHUS [50]. Likewise, we propose this can be extrapolated not only to our case, but to all cases of complement-driven Purtscher-like retinopathy. As previously mentioned, the patient was known to carry a mutation in the $C F H$ gene which codes for a serum protein that regulates the alternative pathway of the complement system in the fluid phase as well as on host cell surfaces by binding through $\mathrm{C} 3 \mathrm{~b}$ and glycosaminoglycans via its C-terminal domain [51]. Mutations in the $C F H$ gene of patients with aHUS are usually heterozygous in nature and cluster in C-terminal domain 19-20. This particular mutation, also found in this patient, results in normal levels of a folded, abnormal protein, that is unable to bind and regulate complement on host cells and platelets. Animal studies have confirmed development of aHUS with high C3 plasma levels in mice lacking the C-terminal end domain of factor $\mathrm{H}$ [52]. In contrast, complete $C F H$ knockout mice develop a different renal disease pattern, namely membranoproliferative glomerulonephritis [53]. These studies support the evidence that the mutant $\mathrm{CFH}$ present in this patient is unable to bind and control complement activation on the glomerular endothelium, basement membrane, platelets and the retinal endothelium, with subsequent development of a procoagulant state that in turn resulted in the development of aHUS and Purtscherlike retinopathy.

Eculizumab, a monoclonal antibody directed against complement protein $\mathrm{C} 5$, prevents activation 


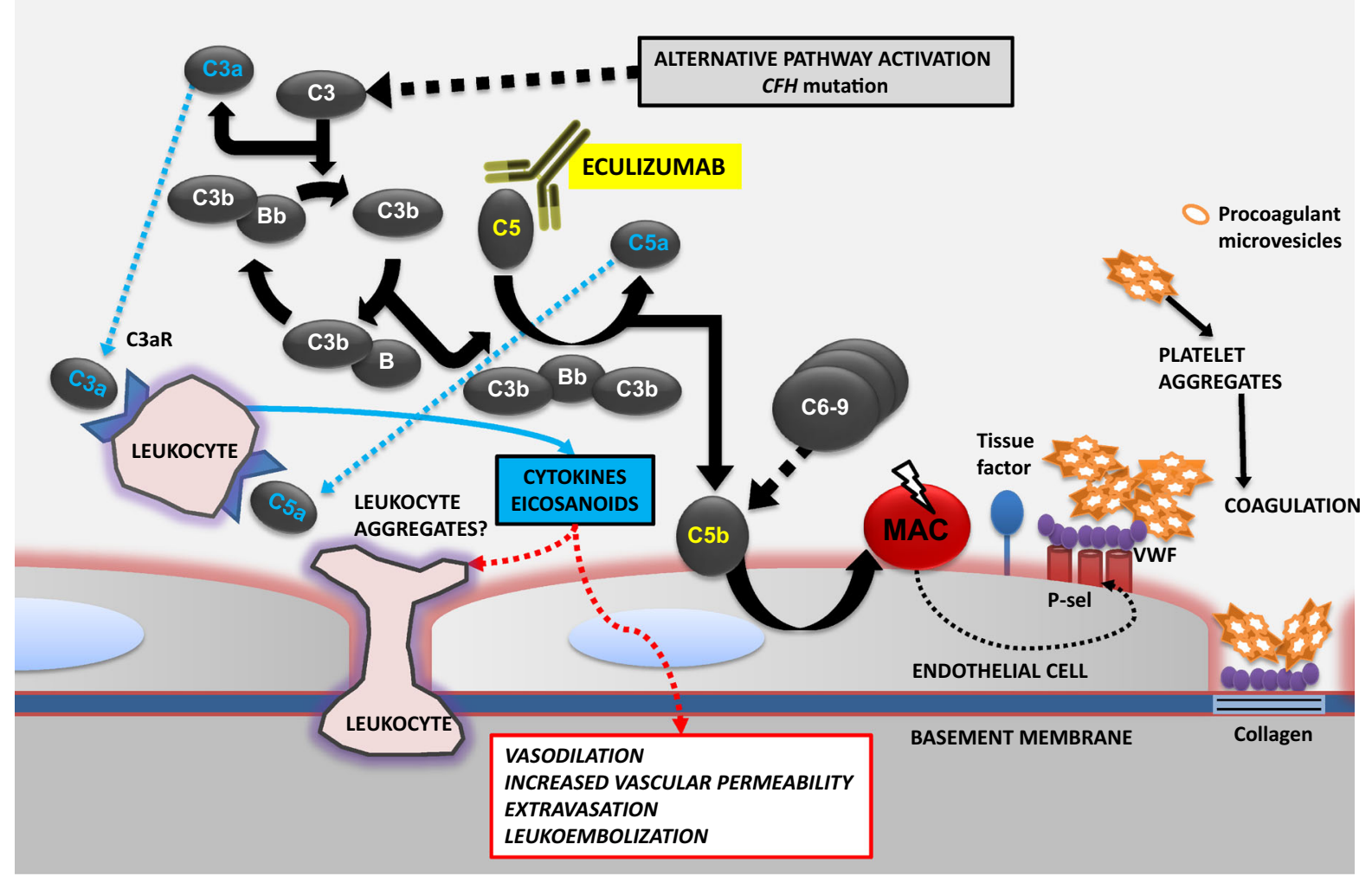

Fig. 4 Proposed pathogenic mechanisms of Purtscher-like retinopathy secondary to uncontrolled complement activation. The alternative pathway activates formation of C3b by C3; C3b interacts with factor $\mathrm{B}$ which is subsequently cleaved by factor $\mathrm{D}$ to form the alternative pathway $\mathrm{C} 3$ convertase $(\mathrm{C} 3 \mathrm{bBb})$. This enzyme complex is covalently attached to the target via $\mathrm{C} 3 \mathrm{~b}$ while $\mathrm{Bb}$ is the catalytic serine protease subunit. Factor $\mathrm{H}$ regulates the alternative pathway by preventing the interaction of $\mathrm{C} 3 \mathrm{~b}$ with factor $\mathrm{B}$, interacting with factor I-mediated cleavage of $\mathrm{C} 3 \mathrm{~b}$ and dissociating the $\mathrm{C} 3$ convertase of the alternative pathway (not shown). Unchecked, the terminal complement pathway is then activated with release of the complement anaphylatoxin C5a and formation of the membrane attack complex (MAC). Eculizumab binds C5 which is then unable to enter the $\mathrm{C} 5$ convertase $(\mathrm{C} 3 \mathrm{bBbC} 3 \mathrm{~b})$, impeding

of the terminal complement cascade and the generation of effector molecules C5a and C5b-9. The ability of eculizumab to suppress complement activity in native and transplanted kidney has revolutionized the care of patients with aHUS [54-56]. Without attenuation of complement activity, either through plasmapheresis, kidney-liver transplant $(\mathrm{CFH}$ and other complement factors are produced in the liver), or eculizumab, disease recurrence occurs in approximately $80 \%$ of $\mathrm{CFH}$ mutation carriers after renal cleavage into the effector molecules, C5a and C5b, and assembly of the terminal complement complex (C5b-9). This leads to exocytosis of adhesion molecules [P-selectin (P-sel)] and von Willebrand factor (VWF) which in turn lead to platelet adhesion and aggregation, expression of tissue factor and activation of the coagulation cascade. Cell detachment exposes the subendothelial matrix, facilitating binding of VWF to collagen with ensuing amplification of the coagulation state. Platelet aggregates release procoagulant microvesicles that contain tissue factor. Receptors for $\mathrm{C} 3 \mathrm{a}$ and $\mathrm{C} 5 \mathrm{a}$ [C3a receptor $(\mathrm{C} 3 \mathrm{aR})$ and $\mathrm{C} 5 \mathrm{a}$ receptor $(\mathrm{C} 5 \mathrm{aR})]$ in polymorphonuclear leukocytes and monocytes, bind these anaphylatoxins and enhance the release of cytokines and eicosanoids contributing to an increase in vascular permeability, vasodilation, leukocyte extravasation and potentially formation of leukocyte aggregates

transplantation since an isolated kidney allograft does not correct the underlying genetic defect [57].

We hypothesize that complement inhibition by means of eculizumab triggered the rapid resolution of clinical findings and dramatic restoration of visual acuity in this patient. We consider it unlikely that an expectant management or other treatment options such as dosage increase of systemic corticosteroids would have resulted in a similar outcome. Nevertheless, we are aware of the limitation of assuming efficacy based 
on results obtained with only one patient. Confirmation of clinical efficacy requires validation from a larger clinical study. In this patient, plasmapheresis was considered as a possible treatment option; however, this would not have had an effect on complement activation which would have resulted in perpetuation of renal and (possibly) retinal findings. Furthermore, the therapeutic effect of systemic corticosteroids in severe Purtscher-like retinopathy is inconsistent, with most studies confirming no differences in visual outcome [1, 4]. Interestingly, this patient developed Purtscher-like retinopathy while on systemic corticosteroids, albeit at a low dosage. It has been suggested that corticosteroids may be inefficient in cases of Purtscher-like retinopathy that are primarily triggered by thrombotic microangiopathy, such as in aHUS [58]. Solely targeting the inflammatory component will not affect microembolization since other complex pathogenic events such as hemostasis, thrombosis and complement dysregulation will remain unanswered [58].

Several clinical parameters support the favorable effect of eculizumab in this particular patient. First, pronounced improvement of visual acuity occurred rapidly after initiation of eculizumab $\left(20 / 200^{-2}\right.$ visual acuity at time of diagnosis improving to 20/15, 8 Snellen lines improvement, 14 days after initial examination). Early resolution of clinical findings is associated with better final visual outcomes [2]. Evidence shows spontaneous visual improvement of at least 2 Snellen lines is likely to occur in half of cases; however, such improvement occurs mostly in patients with better visual acuity at presentation, whereas poor visual acuity at presentation, such as observed in this patient, is regarded as a poor prognostic sign for visual improvement [2]. Secondly, this patient had other established poor prognostic criteria [4], namely female gender and intraretinal macular edema at presentation.

Severe visual loss in Purtscher and Purtscher-like retinopathies is likely secondary to macular edema [4]. Moreover, the duration of retinal changes is the most important parameter for full recovery of vision and prevention of secondary development of retinal pigment epithelium and retinal nerve fiber layer atrophy with subsequent loss of differentiation between retinal layers [59]. Therefore, early reduction of macular edema should be a priority in order to prevent progression to end-stage degenerative changes.
Mutations in complement-associated genes, and particularly in the $C F H$ gene, have been shown to be associated with age-related macular degeneration (AMD), one of the leading causes of blindness worldwide [60]. Several mutations in complementassociated genes reported in patients with aHUS patients, such as Arg1210Cys in $\mathrm{CFH}$, were found to confer a high risk of AMD development [61]. The relevance of this shared genetic association between two distinct clinical phenotypes remains unknown. Retrospective analyses of AMD databases did not reveal a higher incidence of renal disorders in carriers of complement gene mutations known to cause both aHUS and AMD [62]. On the other hand, patients afflicted with membranoproliferative glomerulonephritis type 2 (MPGN2), a renal disease that is also associated with $\mathrm{CFH}$ mutations, show AMD-like features [63]. This suggests compound (genetic or environmental) factors may influence the final clinical outcome. Indeed, AMD and MPGN2 share a common pathogenic mechanism, i.e., the deposition of complement-containing material beneath the retinal pigment epithelium in AMD and along the glomerular basement membrane in MPGN2 [63]. On the other hand, the pathogenic mechanisms causative of Purtscher-like retinopathy are shared with those of aHUS, namely endothelial injury, activation of the coagulation cascade and ultimately thromboembolic microangiopathy [52]. Moreover, aHUS patients may carry multiple complement factor gene mutations, which could imply different cellular pathogenic mechanisms [64]. Cross-phenotype studies are required in order to understand similarities and differences in complement-mediated pathogenic mechanisms of both aHUS and AMD. This could elucidate the effects of eculizumab and other complement-modulating agents in the treatment of AMD and other ophthalmic diseases. A recent phase 2 study demonstrated that eculizumab failed to arrest progression of geographic atrophy (GA) when administered for 24 weeks to patients with dry AMD (COMPLETE study) [65]. It is likely that, although complement dysregulation is knowingly associated with AMD, pathogenesis and progression of GA may occur independently of complement overactivation [66]. In our case report, uncontrolled complement activation had a direct effect as a facilitator and trigger of the retinal thromboembolic microangiopathy, and therefore, it is highly probable that local complement 
inhibition by systemic eculizumab enabled the rapid resolution of the retinal microembolization with ensuing resolution of the intraretinal macular edema. These complement-mediated effects differ from those attributed to the complement pathway in diseases characterized by deposition of extracellular material such as AMD and MPGN2. Complement inhibition has been demonstrated to occur within $1 \mathrm{~h}$ after administration of eculizumab [55]. Therefore, eculizumab may be more efficacious in suppressing acute complement-mediated changes such as thromboembolic microangiopathy of retinal and renal vessels, as opposed to chronic changes induced by uncontrolled complement activation such as in AMD. The authors of the COMPLETE study argue that intravitreal administration of eculizumab might have resulted in a more favorable outcome. Our case provides indirect evidence that systemic eculizumab, at the administered dosage, does reach therapeutic concentrations at the level of the choroid and is able to penetrate the RPE and retina. In addition, the dosing regimen used for treatment of aHUS has been shown to reach drug complement-inhibiting concentrations in the peripheral blood [56].

The description of this case raises the possibility that eculizumab may be a valid therapeutic strategy in severe cases of Purtscher-like retinopathy in which the primary pathogenic trigger is attributed to dysregulated complement activity. The benefit of intervention over expectant management can only be convincingly assessed with a randomized clinical trial, which, given the rarity of the disease and the extreme high cost of the drug (about US $\$ 350.000$ per patient per year), is unlikely. The dramatic and rapid visual recovery demonstrated in this patient, even in the presence of established poor prognostic signs, namely poor visual acuity at presentation, intraretinal macular edema and female gender, provides convincing evidence that eculizumab was causally related to the attained superior outcome. To the best of our knowledge, this is the first report in the literature of eculizumab as a potential therapeutic strategy in Purtscher-like retinopathy.

\section{Compliance with ethical standards}

Conflict of interest Author JERC declares that he has no conflict of interest. Author ROS declares that he has no conflict of interest. Author MO declares that he has no conflict of interest. Author FJB declares that she has no conflict of interest. Author MS declares that she has no conflict of interest.
Human and animal participants All procedures performed in studies involving human participants were in accordance with the ethical standards of the institutional and national research committee and with the 1964 Helsinki Declaration and its later amendments or comparable ethical standards.

Informed consent Informed consent was obtained from all individual participant included in the study.

Open Access This article is distributed under the terms of the Creative Commons Attribution 4.0 International License (http:// creativecommons.org/licenses/by/4.0/), which permits unrestricted use, distribution, and reproduction in any medium, provided you give appropriate credit to the original author(s) and the source, provide a link to the Creative Commons license, and indicate if changes were made.

\section{References}

1. Agrawal A, McKibbin MA (2006) Purtscher's and Purtscher-like retinopathies: a review. Surv Ophthalmol 51(2):129-136. doi:10.1016/j.survophthal.2005.12.003

2. Agrawal A, McKibbin M (2007) Purtscher's retinopathy: epidemiology, clinical features and outcome. Br J Ophthalmol 91(11):1456-1459. doi:10.1136/bjo.2007.117408

3. Pina JP, Ssi-Yan-Kai K, de Monchy I, Charpentier B, Offret H, Labetoulle M (2008) Purtscher-like retinopathy: case report and review of the literature. J Fr D Ophtalmol 31(6):609-613

4. Miguel AIM, Henriques F, Azevedo LFR, Loureiro AJR, Maberley DAL (2013) Systematic review of Purtscher's and Purtscher-like retinopathies. Eye 27(1):1-13. doi:10.1038/ eye.2012.222

5. Behrensbaumann W, Scheurer G (1991) M-Purtscher-range of clinical manifestations and pathogenesis. Klin Monatsbl Augenh 198(2):99-107. doi:10.1055/s-2008-1045938

6. Scheurer G, Praetorius G, Damerau B, Behrens-Baumann W (1992) Vascular occlusion of the retina: an experimental model. I. Leukocyte aggregates. Graefes Arch Clin Exp Ophthalmol 230(3):275-280

7. Schroer H, Scheurer G, Behrens-Baumann W (1992) Vascular occlusion of the retina-an experimental model. II. Platelet aggregates. Graefes Arch Clin Exp Ophthalmol 230(3):281-285

8. Wilkinson WS, Morgan CM, Baruh E, Gitter KA (1989) Retinal and choroidal vascular occlusion secondary to corticosteroid embolisation. Br J Ophthalmol 73(1):32-34

9. Lemagne JM, Michiels X, Vancausenbroeck S, Snyers B (1990) Purtscher-like retinopathy after retrobulbar anesthesia. Ophthalmology 97(7):859-861

10. Blodi BA, Williams CA (1997) Purtscher-like retinopathy after uncomplicated administration of retrobulbar anesthesia. Am J Ophthalmol 124(5):702-703

11. Lim BA, Ang CL (2001) Purtscher-like retinopathy after retrobulbar injection. Ophthalmic Surg Las 32(6):477-478

12. Blodi BA, Johnson MW, Gass JD, Fine SL, Joffe LM (1990) Purtscher's-like retinopathy after childbirth. Ophthalmology 97(12):1654-1659 
13. Lai JC, Johnson MW, Martonyi CL, Till GO (1997) Complement-induced retinal arteriolar occlusions in the cat. Retina 17(3):239-246

14. Sacks T, Moldow CF, Craddock PR, Bowers TK, Jacob HS (1978) Oxygen radicals mediate endothelial cell damage by complement-stimulated granulocytes. An in vitro model of immune vascular damage. J Clin Invest 61(5):1161-1167. doi:10.1172/JCI109031

15. Nautiyal A, Amescua G, Jameson A, Gradowski JF, Hong FY, Doft B (2009) Sudden loss of vision: Purtscher retinopathy in multiple myeloma. Can Med Assoc J 181(12):E277-E277. doi:10.1503/cmaj.081968

16. Harrison TJ, Abbasi CO, Khraishi TA (2011) Purtscher retinopathy: an alternative etiology supported by computer fluid dynamic simulations. Invest Ophthalmol Vis Sci 52(11):8102-8107. doi:10.1167/iovs.11-7734

17. Stewart MW, Brazis PW, Guier CP, Thota SH, Wilson SD (2007) Purtscher-like retinopathy in a patient with HELLP syndrome. Am J Ophthalmol 143(5):886-887. doi:10.1016/ j.ajo.2006.12.005

18. Mayer C, Khoramnia R (2011) Purtscher-like retinopathy caused by acute pancreatitis. Lancet 378(9803):1653. doi:10.1016/S0140-6736(11)60474-1

19. Becheur H, Machevin L, Mostefa-Kara N, Zahedi R (2001) Purtscher' ischemic retinopathy consecutive to an acute pancreatitis. Gastroenterol Clin Biol 25(10):922-924

20. Bui SK, O'Brien JM, Cunningham ET Jr (2001) Purtscher retinopathy following drug-induced pancreatitis in an HIVpositive patient. Retina 21(5):542-545

21. Fumex L, Boizard Y, Burillon C, Denis P (2004) Purtscher retinopathy in acute alcoholic pancreatitis. A case report. J Fr Ophtalmol 27(8):927-931

22. Carrera CR, Pierre LM, Medina FM, Pierre-Filho Pde T (2005) Purtscher-like retinopathy associated with acute pancreatitis. Sao Paulo Med J 123(6):289-291. doi:10. 1590/S1516-31802005000600008

23. Krahulec B, Stefanickova J, Hlinst'akova S, Hirnerova E, Kosmalova V, Hasa J, Pesko K, Strmen P, Dukat A (2008) Purtscher-like retinopathy-a rare complication of acute pancreatitis. Vnitr Lek 54(3):276-281

24. Bhan K, Ashiq A, Aralikatti A, Menon KV, McKibbin M (2008) The incidence of Purtscher retinopathy in acute pancreatitis. Br J Ophthalmol 92(1):151-153. doi:10.1136/ bjo.2006.112847

25. Jeon SY, Jung E, Seol HJ, Hur YJ (2013) Development of Purtscher-like retinopathy after pre-eclampsia combined with acute pancreatitis. Obstet Gynecol Sci 56(4):261-264. doi:10.5468/ogs.2013.56.4.261

26. Tabandeh H, Rosenfeld PJ, Alexandrakis G, Kronish JP, Chaudhry NA (1999) Purtscher-like retinopathy associated with pancreatic adenocarcinoma. Am J Ophthalmol 128(5):650-652

27. Wu C, Dai RP, Dong FT, Wang Q (2014) Purtscher-like retinopathy in systemic lupus erythematosus. Am J Ophthalmol 158(6):1335-1341. doi:10.1016/j.ajo.2014.09.001

28. Stoumbos VD, Klein ML, Goodman S (1992) Purtscher'slike retinopathy in chronic renal failure. Ophthalmology 99(12):1833-1839

29. Zwolinska D, Medynska A, Galar A, Turno A (2000) Purtscher-like retinopathy in nephrotic syndrome associated with mild chronic renal failure. Pediatr Nephrol 15(1-2):82-84
30. Ong T, Nolan W, Jagger J (2005) Purtscher-like retinopathy as an initial presentation of thrombotic thrombocytopenic purpura: a case report. Eye (Lond) 19(3):359-361. doi:10. 1038/sj.eye.6701491

31. Patel MR, Bains AK, O’Hara JP, Kallab AM, Marcus DM (2001) Purtscher retinopathy as the initial sign of thrombotic thrombocytopenic purpura/hemolytic uremic syndrome. Arch Ophthalmol 119(9):1388-1389

32. Power MH, Regillo MC, Custis PH (1997) Thrombotic thrombocytopenic purpura associated with purtscher retinopathy. Arch Ophthalmol 115(1):128-129

33. Tajunisah I, Patel DK, Subrayan V (2010) Purtscher retinopathy as an initial presentation of thrombotic thrombocytopenic purpura. $\mathrm{J}$ Thromb Thrombolysis 30(1):112-113. doi:10.1007/s11239-009-0399-y

34. Lauer AK, Klein ML, Kovarik WD, Palmer EA (1998) Hemolytic uremic syndrome associated with Purtscher-like retinopathy. Arch Ophthalmol 116(8):1119-1120

35. Myers JP, Di Bisceglie AM, Mann ES (2001) Cryoglobulinemia associated with Purtscher-like retinopathy. Am J Ophthalmol 131(6):802-804

36. Sauer A, Nasica X, Zorn F, Petitjean P, Bader P, SpeegSchatz C, Lenoble P (2007) Cryoglobulinemia revealed by a Purtscher-like retinopathy. Clin Ophthalmol 1(4):555-557

37. Chebil A, Mammouri R, Abdallah MB, El Matri L (2016) Purtscher-like Retinopathy as a Rare Presentation of Cryoglobulinemia. Middle East Afr J Ophthalmol 23(2):219-221. doi:10.4103/0974-9233.177409

38. Hollo G (2008) Frequency of Purtscher's retinopathy. Br J Ophthalmol 92(8):1159

39. Yan Y, Shen X (2013) Purtscher-like retinopathy associated with dermatomyositis. BMC Ophthalmol 13:36. doi:10. 1186/1471-2415-13-36

40. Atabay C, Kansu T, Nurlu G (1993) Late visual recovery after intravenous methylprednisolone treatment of Purtscher's retinopathy. Ann Ophthalmol 25(9):330-333

41. Nautiyal A, Amescua G, Jameson A, Gradowski JF, Hong F, Doft B (2009) Sudden loss of vision: Purtscher retinopathy in multiple myeloma. CMAJ 181(12):E277. doi:10.1503/ cmaj.081968

42. Wang AG, Yen MY, Liu JH (1998) Pathogenesis and neuroprotective treatment in Purtscher's retinopathy. Jpn J Ophthalmol 42(4):318-322

43. Constantinescu AR, Bitzan M, Weiss LS, Christen E, Kaplan BS, Cnaan A, Trachtman H (2004) Non-enteropathic hemolytic uremic syndrome: causes and short-term course. Am J Kidney Dis 43(6):976-982. doi:10.1053/j. ajkd.2004.02.010

44. Noris M, Remuzzi G (2009) Atypical hemolytic-uremic syndrome. N Engl J Med 361(17):1676-1687. doi:10.1056/ NEJMra0902814

45. Laure AK, Klein ML, Kovarik WD, Palmer EA (1998) Hemolytic uremic syndrome associated with purtscher-like retinopathy. Arch Ophthalmol-Chic 116(8):1119-1120

46. Patel MR, Bains AK, O'Hara JP, Kallab AM, Marcus DM (2001) Purtscher retinopathy as the initial sign of thrombotic thrombocytopenic purpura/hemolytic uremic syndrome. Arch Ophthalmol-Chic 119(9):1388-1389

47. Sturm V, Menke MN, Landau K, Laube GF, Neuhaus TJ (2010) Ocular involvement in paediatric haemolytic 
uraemic syndrome. Acta Ophthalmol 88(7):804-807. doi:10.1111/j.1755-3768.2009.01552.x

48. Jacob HS, Goldstein IM, Shapiro I, Craddock PR, Hammerschmidt DE, Weissmann G (1981) Sudden blindness in acute pancreatitis. Possible role of complement-induced retinal leukoembolization. Arch Intern Med 141(1): 134-136

49. Shapiro I, Jacob HS (1982) Leukoembolization in ocular vascular occlusion. Ann Ophthalmol 14(1):60-62

50. Noris M, Remuzzi G (2015) Glomerular diseases dependent on complement activation, including atypical hemolytic uremic syndrome, membranoproliferative glomerulonephritis, and C3 Glomerulopathy: core curriculum 2015. Am J Kidney Dis 66(2):359-375. doi:10.1053/j.ajkd.2015. 03.040

51. Schmidt CQ, Herbert AP, Kavanagh D, Gandy C, Fenton CJ, Blaum BS, Lyon M, Uhrin D, Barlow PN (2008) A new map of glycosaminoglycan and C3b binding sites on factor H. J Immunol 181(4):2610-2619

52. Pickering MC, de Jorge EG, Martinez-Barricarte R, Recalde S, Garcia-Layana A, Rose KL, Moss J, Walport MJ, Cook HT, de Cordoba SR, Botto M (2007) Spontaneous hemolytic uremic syndrome triggered by complement factor $\mathrm{H}$ lacking surface recognition domains. J Exp Med 204(6):1249-1256. doi:10.1084/jem.20070301

53. Pickering MC, Cook HT, Warren J, Bygrave AE, Moss J, Walport MJ, Botto M (2002) Uncontrolled C3 activation causes membranoproliferative glomerulonephritis in mice deficient in complement factor $H$. Nat Genet 31(4):424-428. doi:10.1038/ng912

54. Fakhouri F, Hourmant M, Campistol JM, Cataland SR, Espinosa M, Gaber AO, Menne J, Minetti EE, Provot F, Rondeau E, Ruggenenti P, Weekers LE, Ogawa M, Bedrosian CL, Legendre CM (2016) Terminal complement inhibitor eculizumab in adult patients with atypical hemolytic uremic Syndrome: a single-arm, open-label trial. Am J Kidney Dis 68(1):84-93. doi:10.1053/j.ajkd.2015.12.034

55. Legendre CM, Licht C, Muus P, Greenbaum LA, Babu S, Bedrosian C, Bingham C, Cohen DJ, Delmas Y, Douglas K, Eitner F, Feldkamp T, Fouque D, Furman RR, Gaber O, Herthelius M, Hourmant M, Karpman D, Lebranchu Y, Mariat C, Menne J, Moulin B, Nurnberger J, Ogawa M, Remuzzi G, Richard T, Sberro-Soussan R, Severino B, Sheerin NS, Trivelli A, Zimmerhackl LB, Goodship T, Loirat C (2013) Terminal complement inhibitor eculizumab in atypical hemolytic-uremic syndrome. N Engl J Med 368(23):2169-2181. doi:10.1056/NEJMoa1208981

56. Noris M, Galbusera M, Gastoldi S, Macor P, Banterla F, Bresin E, Tripodo C, Bettoni S, Donadelli R, Valoti E, Tedesco F, Amore A, Coppo R, Ruggenenti P, Gotti E, Remuzzi G (2014) Dynamics of complement activation in aHUS and how to monitor eculizumab therapy. Blood 124(11):1715-1726. doi:10.1182/blood-2014-02-558296

57. Kavanagh D, Goodship TH (2010) Atypical hemolytic uremic syndrome. Curr Opin Hematol 17(5):432-438. doi:10.1097/MOH.0b013e32833cae86

58. Yusuf IH, Watson SL (2013) Purtscher retinopathies: are we aiming at the wrong target? Eye 27(6):783-785. doi:10. 1038/eye.2013.47
59. Holak HM, Holak S (2007) Prognostic factors for visual outcome in Purtscher retinopathy. Surv Ophthalmol 52(1):117-118. doi:10.1016/j.survophthal.2006.10.012

60. Despriet DD, Klaver CC, Witteman JC, Bergen AA, Kardys I, de Maat MP, Boekhoorn SS, Vingerling JR, Hofman A, Oostra BA, Uitterlinden AG, Stijnen T, van Duijn CM, de Jong PT (2006) Complement factor H polymorphism, complement activators, and risk of age-related macular degeneration. JAMA 296(3):301-309. doi:10.1001/jama. 296.3.301

61. Zhan XW, Larson DE, Wang CL, Koboldt DC, Sergeev YV, Fulton RS, Fulton LL, Fronick CC, Branham KE, BraggGresham J, Jun G, Hu YN, Kang HM, Liu DJ, Othman M, Brooks M, Ratnapriya R, Boleda A, Grassmann F, von Strachwitz C, Olson LM, Buitendijk GHS, Hofman A, van Duijn CM, Cipriani V, Moore AT, Shahid H, Jiang YD, Conley YP, Morgan DJ, Kim IK, Johnson MP, Cantsilieris S, Richardson AJ, Guymer RH, Luo HR, Ouyang H, Licht C, Pluthero FG, Zhang MM, Zhang K, Baird PN, Blangero J, Klein ML, Farrer LA, DeAngelis MM, Weeks DE, Gorin MB, Yates JRW, Klaver CCW, Pericak-Vance MA, Haines JL, Weber BHF, Wilson RK, Heckenlively JR, Chew EY, Stambolian D, Mardis ER, Swaroop A, Abecasis GR (2013) Identification of a rare coding variant in complement 3 associated with age-related macular degeneration. Nat Genet 45(11):1375-1379. doi:10.1038/ng.2758

62. Duvvari MR, Paun CC, Buitendijk GH, Saksens NT, Volokhina EB, Ristau T, Schoenmaker-Koller FE, van de Ven JP, Groenewoud JM, van den Heuvel LP, Hofman A, Fauser S, Uitterlinden AG, Klaver CC, Hoyng CB, de Jong EK, den Hollander AI (2014) Analysis of rare variants in the $\mathrm{C} 3$ gene in patients with age-related macular degeneration. PLoS ONE 9(4):e94165. doi:10.1371/journal.pone. 0094165

63. Mullins RF, Aptsiauri N, Hageman GS (2001) Structure and composition of drusen associated with glomerulonephritis: implications for the role of complement activation in drusen biogenesis. Eye 15:390-395

64. Esparza-Gordillo J, Goicoechea de Jorge E, Buil A, Carreras Berges L, Lopez-Trascasa M, Sanchez-Corral P, Rodriguez de Cordoba S (2005) Predisposition to atypical hemolytic uremic syndrome involves the concurrence of different susceptibility alleles in the regulators of complement activation gene cluster in 1q32. Hum Mol Genet 14(5):703-712. doi:10.1093/hmg/ddi066

65. Yehoshua Z, de Amorim Garcia Filho CA, Nunes RP, Gregori G, Penha FM, Moshfeghi AA, Zhang K, Sadda S, Rosenfeld PJ (2014) Systemic complement inhibition with eculizumab for geographic atrophy in age-related macular degeneration: the COMPLETE study. Ophthalmology 121(3):693-701. doi:10.1016/j.ophtha.2013.09.044

66. Ferris FL 3rd, Wilkinson CP, Bird A, Chakravarthy U, Chew E, Csaky K, Sadda SR, Beckman Initiative for Macular Research Classification C (2013) Clinical classification of age-related macular degeneration. Ophthalmology 120(4):844-851. doi:10.1016/j.ophtha.2012.10.036 